\title{
Severe holocord syrinx in a child with megalencephaly-capillary malformation syndrome
}

\author{
Devorah Segal, MD, PhD, ${ }^{1}$ Robert F. Heary, MD, ${ }^{2}$ Sanjeev Sabharwal, MD, MPH, ${ }^{3}$ \\ Maureen T. Barry, MD, ${ }^{4}$ and Xue Ming, MD, $\mathrm{PhD}^{1}$ \\ Departments of ${ }^{1}$ Neurology, ${ }^{2}$ Neurological Surgery, ${ }^{3}$ Orthopedics, and ${ }^{4}$ Radiology, Rutgers New Jersey Medical School, Newark, \\ New Jersey
}

\begin{abstract}
The authors present the case of a child with megalencephaly-capillary malformation syndrome who developed a rapidly progressive holocord syringomyelia that was treated surgically. A 3-year-old boy with megalencephaly-capillary malformation-polymicrogyria (MCAP) syndrome presented with several months of right leg weakness, worsening scoliosis, and increased seizures. An MRI study of the brain demonstrated a Chiari I malformation and massively dilated syringomyelia extending from C-2 to the conus medullaris. The patient underwent an urgent suboccipital craniectomy with $\mathrm{C} 1-3$ laminectomies to relieve the CSF outflow obstruction with significant clinical improvement. Surgery was complicated by bleeding from intracranial vascular malformations. This report describes a very rapidly developing, massive holocord syringomyelia related to CSF obstruction due to an unusual congenital brain malformation and associated vascular overgrowth at the site. Serial, premorbid MRI studies demonstrated the very rapid progression from no Chiari malformation, to progressively greater cerebellar tonsillar herniation, to holocord syrinx. This complication has never been reported in MCAP syndrome and should be considered in any affected MCAP patient with a progressive neurological decline, even if previous spine imaging findings were normal. Surgical complications due to hemorrhage also need to be considered in this vascular brain malformation.
\end{abstract}

http://thejns.org/doi/abs/10.3171/2016.1.PEDS15482

KEY WORDS megalencephaly-capillary malformation syndrome; MCAP; macrocephaly-cutis marmorata telangiectasia congenita; syringomyelia; Chiari I malformation; congenital

$\mathrm{M}$ EGALENCEPHALY-CAPILLARY malformation-polymicrogyria (MCAP) syndrome, also known as macrocephaly-capillary malformation, is a rare disorder characterized by a spectrum of abnormalities, including megalencephaly, brain and body hemihypertrophy, polymicrogyria, cutaneous vascular malformations, and connective tissue dysplasia. Treatment is symptomatic, and the natural history of this disorder is still being clarified. In the limited number of MCAP cases reported worldwide, no common genetic defect has been found among cases. Several diagnostic criteria have been proposed ${ }^{3,4,69,10,12,15}$ with substantial overlap. Common neuroimaging findings include ventriculomegaly, cavum septum pellucidum, cerebellar tonsillar herniation, and cerebral and/or cerebellar asymmetry. ${ }^{9}$ Children with MCAP often have developmental delay, behavior problems, and somatic asymmetry. ${ }^{9,10}$
Several patients have been described as having cardiovascular anomalies such as internal hemangiomas, ${ }^{10}$ and some have dilated transverse sinus. ${ }^{2}$ A single case of small lumbar syrinx has been reported in MCAP. ${ }^{1}$ Here, we report a case of unusual holocord syrinx that developed concomitantly with a progressive cerebellar tonsillar herniation and CSF obstruction, and we describe the surgical difficulties associated with the highly vascular nature of this brain malformation.

\section{Case Report}

This male patient is the first child of nonconsanguineous, healthy Middle-Eastern parents with no family history of developmental or genetic disorders. He was born at 37 weeks' gestation via cesarean section because of fetal macrosomy that was diagnosed on prenatal ultrasound, 
with a birth weight of $3.94 \mathrm{~kg}$ (97th percentile). He was noted to have a large head at birth ( $>97$ th percentile) with frontal bossing, but a cranial ultrasound detected only benign extraaxial hydrocephalus. Also noted at birth were truncal hypotonia, syndactyly of the left second and third toes, a wide gap between the toes on both feet, and diffuse erythematous, blanching skin hyperpigmentation.

At 2 months of age, he had 2 seizures, and he was seen in our hospital by the genetics and pediatric neurology teams. Comparative genomic hybridization microarray was normal. MCAP was diagnosed in the child based on his classic physical findings, which met the clinical diagnostic criteria for MCAP, and a lack of any other identified genetic abnormality, and he started receiving phenobarbital for control of the seizures. MRI of the brain showed asymmetrical frontal horns of the lateral ventricles, right smaller than left, a cavum septum pellucidum, and minimal enlargement of the right cerebral hemisphere compared with the left (Fig. 1A and B). There was no syrinx in the visible portion of the cervical spinal cord.

The patient's seizures were well controlled with phenobarbital, and he continued to make developmental progress, although with moderate language and gross motor delays. His facial asymmetry and overall right-sided hemihypertrophy became more evident with age, and he developed a leg-length discrepancy and scoliosis. MRI of the
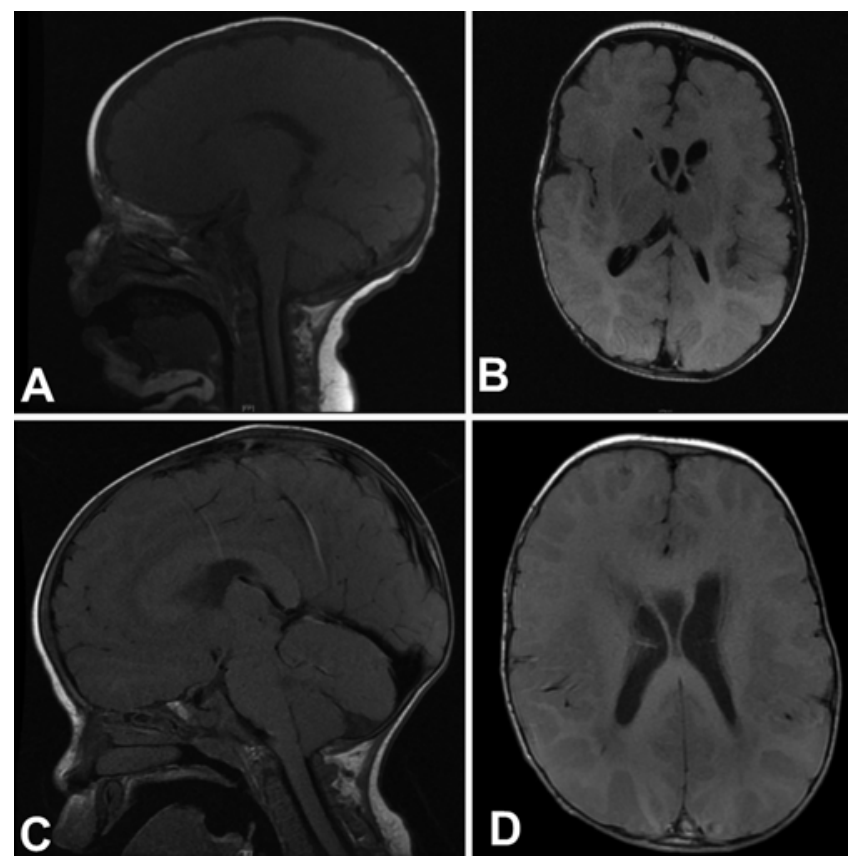

FIG. 1. Sagittal T1-weighted (A) and axial FLAIR (B) images of the brain obtained at 2 months, showing asymmetrical frontal horns of the lateral ventricles, right smaller than left, a cavum septum pellucidum, and minimal enlargement of the right cerebral hemisphere compared with the left. No Chiari I malformation or syrinx is visible. Sagittal T1-weighted (C) and axial FLAIR (D) images of the brain obtained at 15 months, showing an enlarged cerebellum with tonsillar herniation and upward herniation of the cerebellum with resulting deep venous congestion. There is now extensive T2 hyperintense signal abnormality in the white matter, suggesting abnormal myelination, as well as multiple foci of polymicrogyria in both hemispheres. Again, no syrinx was seen in the visible portion of the cervical spinal cord. brain was repeated at 15 months of age as part of routine monitoring for a patient with MCAP (Fig. 1C and D). This MRI study showed an enlarged cerebellum with tonsillar herniation and upward herniation of the cerebellum with resulting deep venous congestion. The asymmetrically enlarged right cerebral hemisphere was more evident, and there was extensive T2 hyperintense signal abnormality in the white matter, suggesting abnormal myelination. The patient also had multiple foci of polymicrogyria in both hemispheres. Again, no syrinx was seen in the visible portion of the cervical spinal cord. The patient was seen by the pediatric neurosurgery team at that time, and as there were no myelopathic signs on examination the decision was made to monitor the patient with serial neurological examination and to repeat MRI in 1 year.

Because of his parents' reluctance to have him sedated, the patient did not undergo recommended annual brain MRI at 2 years. At 3 years 6 months of age, he had increased difficulty walking and seemed to be dragging his right leg. He had no signs or symptoms of increased intracranial pressure, such as vomiting, headache, or lethargy. Neurological examination demonstrated a right foot drop and weakness of right hip flexion and the proximal muscles of his right arm. He had no papilledema on examination. The patient was seen by the pediatric orthopedics team at that time as well, and his scoliotic curvature had increased from $14^{\circ}$ to $23^{\circ}$ over a 1 -year period. In addition, after being seizure free for 2 years, he began having seizures again, and he required escalating doses of levetiracetam and occasional rectal diazepam for prolonged focal seizures. MRI of the brain and entire spinal axis demonstrated an increased extent of the low-lying cerebellar tonsils, unchanged asymmetrical enlargement of the right cerebral hemisphere, and upward herniation of the cerebellum with diffuse polymicrogyria (Fig. $2 \mathrm{~A}$ and $\mathrm{B})$. There was no increased ventriculomegaly or transependymal CSF flow. In addition, a massively dilated syringomyelia, measuring up to $15 \mathrm{~mm}$ in diameter and extending from the $\mathrm{C}-2$ level to the conus medullaris, was now identified (Fig. 2C and D). There was effacement of CSF at the skull base, suggesting outflow obstruction, and a low conus medullaris at the L2-3 level.

Upon review of this new MRI study, we considered placing a ventriculoperitoneal shunt but planned instead to decompress the cervicomedullary junction to relieve the patient's symptoms. The patient underwent an immediate suboccipital craniectomy with $\mathrm{C} 1-2$ laminectomies to decompress the obex and cervicomedullary junction. The suboccipital craniectomy included removing bone 3 $\mathrm{cm}$ from the foramen magnum superiorly, stopping below the torcular herophili, with a width of $18 \mathrm{~mm}$. The C-1 laminectomy was $16 \mathrm{~mm}$ and centered over the midline, and the C-2 laminectomy was $15 \mathrm{~mm}$ and centered over the midline. The dura was opened during surgery in a Yshape to expose the cerebellar tonsils, the brainstem, and the upper cervical spinal cord. The cerebellum was under a moderate degree of increased pressure. Using the operating microscope, arachnoid adhesions were released between the lateral aspect of the cerebellar tonsils and the adjacent dura mater as well as between the cerebellar tonsils themselves. Ultrasonography was not needed as 

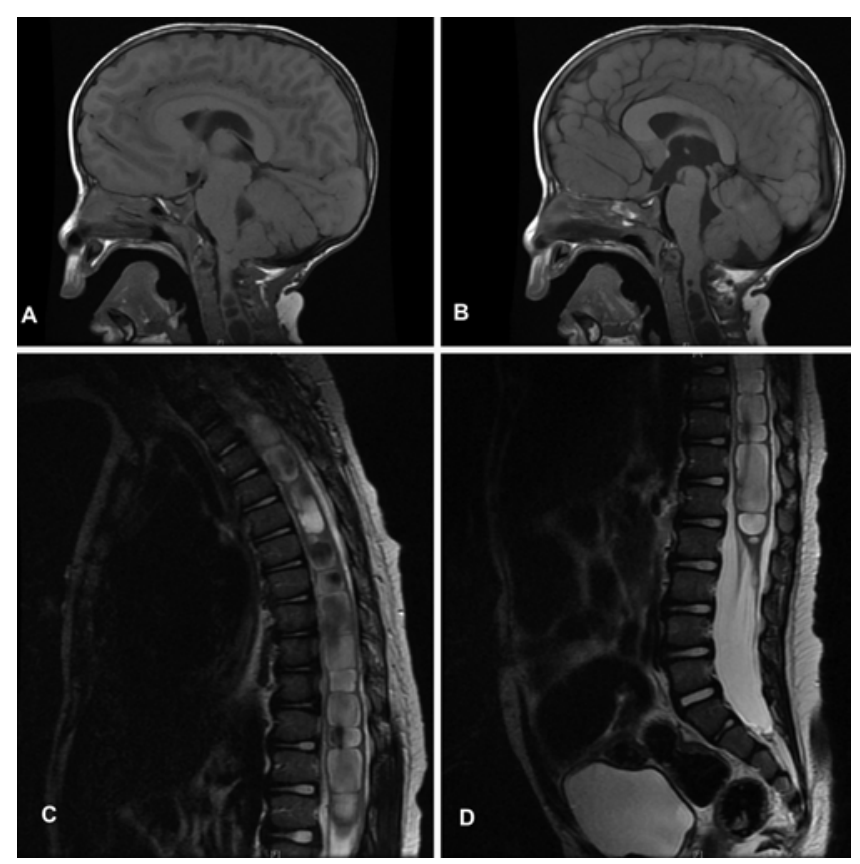

FIG. 2. Sagittal T1-weighted MR images of the brain obtained at 3 years 9 months of age, demonstrating an increased extent of the low-lying cerebellar tonsils and upward herniation of the cerebellum with diffuse polymicrogyria (A and B). There is effacement of CSF at the skull base, suggesting outflow obstruction. Sagittal T2-weighted thoracic (C) and lumbar (D) MR images of the spine obtained at the same time, showing a massively dilated syringomyelia, measuring up to $15 \mathrm{~mm}$ in diameter and extending from the C-2 level to the conus medullaris, and a low conus medullaris at the $\mathrm{L} 2-3$ level.

the obex was directly visualized. A duraplasty graft was placed and secured at multiple locations around the perimeter; however, a watertight closure was not performed. The tonsils were not shrunken.

During surgery, the patient developed hemorrhage that was difficult to control. The cerebellum had multiple small bleeding vessels that appeared to be capillary malformations. These required multiple small hemoclips and electrocauterization to achieve hemostatic control. After being replenished with $3 \mathrm{~L}$ of blood, the patient was finally hemodynamically stabilized and was kept sedated for several days to enable clot formation. A CT angiogram after surgery showed no arteriovenous malformations or cerebral aneurysms, but there were bilateral cerebellar developmental venous anomalies and multiple small venous channels within both cerebral hemispheres. Postoperatively, the patient had a persistent CSF collection at the surgical site and required ventriculoperitoneal shunt placement for CSF diversion.

At follow-up 9 months later, the patient's walking had improved, and his seizures were once again controlled. Neurological examination revealed resolution of the right foot drop and improved arm strength, although the patient still had mild proximal bilateral arm weakness. His scoliosis and leg-length discrepancy had decreased, and he was able to use a shorter lift on his shoe. His language development continued to improve as well. Follow-up evaluation at 18 months after surgery demonstrated continued developmental progress and improvement in his gait and upper- and lower-extremity strength. Follow-up MRI of the spine 6 months postoperatively demonstrated an essentially unchanged holocord syrinx. A repeat MRI study at 1 year after surgery demonstrated that the lower cervical and thoracic syringes have decreased in size, and there is more CSF signal seen dorsally in each of these locations. The upper cervical syrinx remains unchanged compared with before surgery, but there is no persistent bony compression.

\section{Discussion}

Megalencephaly-capillary malformation-polymicrogyria syndrome, also known as macrocephaly-capillary malformation or macrocephaly-cutis marmorata telangiectasia congenita is a rare syndrome that includes neurological, cutaneous, and somatic overgrowth manifestations. It is presumed to be genetic in origin; however, no common genetic defect has yet been found, ${ }^{9}$ although a subset of these patients may have PIK3CA mutations. ${ }^{11}$ It appears likely that many of these patients are genetic mosaics, with abnormalities manifesting in the tissues that carry a mutation. ${ }^{11}$ This disorder is characterized by a spectrum of abnormalities, including megalencephaly, cerebral and somatic hemihypertrophy, polymicrogyria, cutaneous vascular malformations, and connective tissue dysplasia. There are several characteristic imaging findings in MCAP, including ventriculomegaly, cavum septum pellucidum, cerebellar tonsillar herniation, and cerebral and/ or cerebellar asymmetry. ${ }^{9}$ Several diagnostic criteria schemata have been proposed ${ }^{3,4,6,9,12,15}$ based on anatomical and radiographic findings, but there is no clear diagnostic consensus yet. Diagnosis is made based on clinical criteria alone. The patient presented in this report had impressive intracranial capillary vascular malformations; these malformations have not been previously reported, although there are reports of other internal vascular anomalies ${ }^{10}$ and dilated transverse sinus. ${ }^{2}$

Chiari I malformations are not a diagnostic criterion of MCAP. However, they have been reported in this disorder as a result of brain overgrowth. ${ }^{14}$ In children, Chiari I malformations may be asymptomatic and do not require surgical correction. ${ }^{7}$ The presence of a syrinx is a relatively common association with Chiari I malformations and may be present in as many as $23 \%$ of these children. ${ }^{13}$ In children, scoliosis is a common presenting symptom of syringomyelia ${ }^{7,8}$ and larger syrinx size appears to increase the risk of scoliosis. ${ }^{5}$ The classic findings associated with cervical syrinx of loss of pain and temperature sensation in a cape-like distribution can be difficult to assess in a young child. More subtle signs, such as clumsiness, difficulty running, or torticollis may be the presenting features in children.? Despite the frequent occurrence of Chiari I malformations in MCAP, we have found only one published account of a syrinx in this disorder, which was a small focal syrinx in the conus. ${ }^{1}$

We describe a child with MCAP who progressed, in 3 years, from having mild cerebral asymmetry to cerebellar enlargement with herniation, to worsened cerebellar tonsil herniation with a massive holocord syringomyelia. What is extremely noteworthy in our case is that there is 
MRI evidence of relatively rapid development of a holocord syrinx with none seen on MR images obtained in the first 2 years of life. At the time of his evaluation at 3 years 9 months, our patient presented with worsening scoliosis, increased seizure frequency, and subtle bilateral weakness, which were all attributable to his syrinx and CSF obstruction. These symptoms all improved postoperatively despite essentially no change in the radiographic size of the syrinx 1 year after surgery. The imaging studies do not demonstrate a decreased syrinx size, for unclear reasons, but the pressure within the syrinx cannot be determined with neuroimaging studies. Thus, it is entirely possible that the patient's improved neurological condition was the result of a lowering of the pressure within this syrinx. A cine MRI study will be obtained during the next MRI session at 24 months after surgery.

In this patient, the syrinx etiology was likely related to his congenital brain malformation and possibly continued overgrowth of vascular malformation. The asymmetry and overgrowth characteristic of MCAP led to a worsening Chiari I malformation. This, combined with the patient's hemimegalencephaly, resulted in obstruction of the obex, leading to impaired CSF flow between the central canal and the fourth ventricle. Syringomyelia needs to be considered in children with brain malformations in general, particularly static or progressive hindbrain abnormalities that can lead to obstruction of CSF flow at the cervicomedullary junction. Children with MCAP and related disorders should initially be screened for syrinx to prevent irreversible damage, and, if neurological deterioration occurs during serial examinations, there should be a low threshold for repeating advanced neuroimaging studies. In addition, our experience with this patient with MCAP leads us to caution neurosurgeons of the potential for surgical complications resulting from hemorrhage in this vascular brain malformation.

\section{References}

1. Carcao M, Blaser SI, Grant RM, Weksberg R, Siegel-Bartelt $\mathrm{J}$ : MRI findings in macrocephaly-cutis marmorata telangiectatica congenita. Am J Med Genet 76:165-167, 1998

2. Conway RL, Pressman BD, Dobyns WB, Danielpour M, Lee $\mathrm{J}$, Sanchez-Lara PA, et al: Neuroimaging findings in macrocephaly-capillary malformation: a longitudinal study of 17 patients. Am J Med Genet A 143A:2981-3008, 2007

3. Franceschini P, Licata D, Di Cara G, Guala A, Franceschini D, Genitori L: Macrocephaly-cutis marmorata telangiectatica congenita without cutis marmorata? Am J Med Genet 90:265-269, 2000

4. Giuliano F, David A, Edery P, Sigaudy S, Bonneau D, Cormier-Daire V, et al: Macrocephaly-cutis marmorata telangiectatica congenita: seven cases including two with unusual cerebral manifestations. Am J Med Genet A 126A:99-103, 2004

5. Godzik J, Kelly MP, Radmanesh A, Kim D, Holekamp TF, Smyth MD, et al: Relationship of syrinx size and tonsillar descent to spinal deformity in Chiari malformation Type I with associated syringomyelia. J Neurosurg Pediatr 13:368-374, 2014
6. Lapunzina P, Gairí A, Delicado A, Mori MA, Torres ML, Goma A, et al: Macrocephaly-cutis marmorata telangiectatica congenita: report of six new patients and a review. Am J Med Genet A 130A:45-51, 2004

7. Luciano MG: Chiari malformation: are children little adults? Neurol Res 33:272-277, 2011

8. Magge SN, Smyth MD, Governale LS, Goumnerova L, Madsen J, Munro B, et al: Idiopathic syrinx in the pediatric population: a combined center experience. J Neurosurg Pediatr 7:30-36, 2011

9. Martínez-Glez V, Romanelli V, Mori MA, Gracia R, Segovia M, González-Meneses A, et al: Macrocephaly-capillary malformation: Analysis of 13 patients and review of the diagnostic criteria. Am J Med Genet A 152A:3101-3106, 2010

10. Mirzaa GM, Conway RL, Gripp KW, Lerman-Sagie T, Siegel DH, deVries LS, et al: Megalencephaly-capillary malformation (MCAP) and megalencephaly-polydactyly-polymicrogyria-hydrocephalus (MPPH) syndromes: two closely related disorders of brain overgrowth and abnormal brain and body morphogenesis. Am J Med Genet A 158A:269-291, 2012

11. Rivière JB, Mirzaa GM, O'Roak BJ, Beddaoui M, Alcantara $\mathrm{D}$, Conway RL, et al: De novo germline and postzygotic mutations in AKT3, PIK3R2 and PIK3CA cause a spectrum of related megalencephaly syndromes. Nat Genet 44:934-940, 2012

12. Robertson SP, Gattas M, Rogers M, Adès LC: Macrocephaly-cutis marmorata telangiectatica congenita: report of five patients and a review of the literature. Clin Dysmorphol 9:1-9, 2000

13. Strahle J, Muraszko KM, Kapurch J, Bapuraj JR, Garton HJ, Maher CO: Chiari malformation Type I and syrinx in children undergoing magnetic resonance imaging. J Neurosurg Pediatr 8:205-213, 2011

14. Tubbs RS, Smyth MD, Wellons JC, Blount JP, Oakes WJ: Cutaneous manifestations and the Chiari I malformation. Pediatr Neurol 29:250-252, 2003

15. Wright DR, Frieden IJ, Orlow SJ, Shin HT, Chamlin S, Schaffer JV, et al: The misnomer "macrocephaly-cutis marmorata telangiectatica congenita syndrome": report of 12 new cases and support for revising the name to macrocephaly-capillary malformations. Arch Dermatol 145:287-293, 2009

\section{Disclosures}

The authors report no conflict of interest concerning the materials or methods used in this study or the findings specified in this paper.

\section{Author Contributions}

Conception and design: Segal, Heary, Sabharwal, Ming. Acquisition of data: Heary, Sabharwal, Barry, Ming. Analysis and interpretation of data: Segal, Barry, Ming. Drafting the article: Segal. Critically revising the article: Segal, Heary, Sabharwal, Ming. Reviewed submitted version of manuscript: all authors. Approved the final version of the manuscript on behalf of all authors: Segal. Study supervision: Heary, Sabharwal, Ming.

\section{Correspondence}

Devorah Segal, NYU Langone Medical Center, The Stephen D. Hassenfeld Children's Center for Cancer \& Blood Disorders, 160 E 32nd St., 2nd Fl., New York, NY 10016. email: devorah. segal@nyumc.org. 